Western University

Scholarship@Western

Education Publications

Education Faculty

2019

\title{
A Comparison of Guided Notes and Video Modules in an Online Course
}

Gabrielle Lee

Western University, glee329@uwo.ca

Follow this and additional works at: https://ir.lib.uwo.ca/edupub

Part of the Education Commons

Citation of this paper:

Lee, G. T. (2019). A Comparison of Guided Notes and Video Modules in an Online Course. International Journal of Online Pedagogy and Course Design (IJOPCD), 9(3), 48-60. 


\title{
A Comparison of Guided Notes and Video Modules in an Online Course
}

Gabrielle Tsai Lee, Michigan State University, East Lansing, USA \& Western University, London, Canada

\begin{abstract}
The purpose of the study was to compare the effects of guided notes versus video modules as a supplement to textbook readings on student quiz scores and to evaluate the overall effectiveness of guided notes in a fully online course. A total of 15 graduate students, aged 22 to 30, participated in this study. The study combined an adapted alternating treatments design and a pretest-posttest design with all participants experienced in both teaching methods in the same sequence. The experimental conditions contained the textbook readings supplemented with guided notes versus video modules. Results indicated both guided notes and video modules were effective, but students' quiz scores were significantly higher under the video modules condition than the guided notes condition. No difference was found in students' perceived helpfulness of the materials, but the students enjoyed video modules significantly more than guided notes.
\end{abstract}

\section{KEYWORDS}

Applied Behavior Analysis, Guided Notes, Higher Education, Online Instruction, Video-Based Instruction

\section{INTRODUCTION}

In recent years, online learning has become an increasingly popular trend in education for learners with various needs and abilities across disciplines. This educational trend is growing fast at the university level. According to the U.S. Department of Education, National Center for Education Statistics (2018), 29\% undergraduate and $34.4 \%$ graduate students took at least one distance education course in the 2015-2016 school year, while only $16 \%$ undergraduate and $17 \%$ graduate students did so in the 2003-2004 school year. Online learning offers flexible and convenient opportunities for learners and is a cost-effective alternative for schools (Buzhardt \& Semb, 2005).

Many of the applied behavior analysis (ABA) programs in universities are offered in a fully online format. Currently, the Behavior Analyst Certification Board (the credentialing agency of ABA programs in universities) has approved 93 fully online ABA programs, which is approximately $32 \%$ of all on-campus and online programs combined (Behavior Analyst Certification Board, 2016). With the increase of online ABA programs in universities, it is imperative to develop and evaluate effective practices for these online courses.

\section{LITERATURE REVIEW}

Research in ABA has traditionally emphasized effective teaching strategies for all learners, including university students. The teaching strategies implemented at the university level were originally evaluated in face-to-face classrooms (e.g., Boyce \& Hineline, 2002; Fienup, Hamelin, 
Reyes-Giordano, \& Falcomata, 2011; Heward, 1994; Keller, 1968). With the explosive advances in technology, Skinner's (1958) teaching machines can be feasibly programmed as part of online instruction. Behavior analysts have attempted to integrate the technology of process (i.e., effective teaching practices derived from behavioral research) into the readily available technology of tools for individualized learning (Twyman, 2015). Thus, recent research efforts in pedagogy have gradually extended from the traditional classroom to the virtual classrooms (Martin, Pear, \& Martin, 2002a; Pear \& Crone-Todd, 1999; Sella, Ribeiro, \& White, 2014; Walker \& Rehfeldt, 2012). For example, Keller's Personalized System of Instruction (PSI) was re-evaluated in web-based learning systems and found effective to improve student performance for college students in the virtual classroom (Martin et al., 2002a; Martin, Pear, \& Martin, 2002b; Pear \& Crone-Todd, 1999).

Several features of PSI have been successfully incorporated into an online format that includes self-paced learning modules, small instructional units, frequent unit quizzes, and a mastery requirement for each unit. However, because of PSI's emphasis on written responses, the use of proctors to provide accurate and timely feedback on frequent quizzes can be quite challenging (Martin et al., 2002b, 2002a). Equivalence-based instruction is also programmed to teach derived relations in a variety of academic subjects at the college level, but empirical support for effective instructional practices to promote derived relations remain limited (Fienup et al., 2011). Despite the challenges, the findings indicate that integrating empirically validated online teaching strategies for individualized instruction, is both feasible and practical. The instruction in the previously mentioned studies consists of multiple teaching strategies derived from behavioral principles designed to engage learners in active participation to make online learning effective. However, many evidence-based practices developed and evaluated in traditional in-person classrooms are still in need of empirical validations when implemented in an online format.

The use of guided notes in traditional classrooms is an evidence-based teaching practice. However, research on the use of guided notes in online learning is limited. Heward (1994) defined guided notes as instructor-prepared incomplete notes with spaces for students to fill out keywords or information during lectures or independent reading. Specifically, students follow the lectures or readings by taking accurate notes on key concepts without missing important information and then use the notes to guide their study. Guided notes are implemented in a wide range of disciplines in universities to promote student engagement and enhance learning (Larwin \& Larwin, 2013; Reed, Rimel, \& Hallett, 2016). Using guided notes in university instruction improved overall student performance in exams, compared to complete notes prepared by the instructors (Neef, McCord, \& Ferreri, 2006) or simply note-taking by students with instructor's handouts (Austin, Lee, Thibeault, \& Bailey, 2002; Bahadourian, Tam, Greer, \& Rousseau, 2006). Besides university instruction, guided notes were also used in elementary and secondary schools to facilitate learning for students in general education and special education (Konrad, Joseph, \& Eveleigh, 2009; Larwin, Dawson, Erickson, \& Larwin, 2012). Since empirical evidence supports the use of guided notes, it may be helpful to adopt this practice to an online format to increase active participation for each student enrolled in an online course.

Since the U.S. Surgeon General and many other authoritative agencies endorsed ABA-based ASD interventions (U.S. Department of Health and Human Services, 1999), the demand for ABA professionals providing autism interventions became increasingly high in recent years. As discussed previously, fully online ABA programs increased dramatically for the purpose of training qualified professionals. Many of these programs are autism-focused ABA programs with instructional content designed specifically for the applications of ABA principles in autism interventions.

Autism Training Solution (ATS), currently in Relias Learning, is one of the online training programs created to provide autism-focused ABA training for professionals, staff, and parents working with individuals with autism. The instructional methods used in ATS are comprised of several effective teaching strategies derived from behavioral research, including sequenced small-units, unit quizzes, unlimited attempts to pass unit quizzes to ensure mastery of content material, video modeling of 
teaching procedures with narratives, and individualized pacing. It also provides a recourse with each training lesson that includes sample lesson plans, data collection forms, and references.

Currently available research suggests that ATS may be an effective tool to provide online training for students and professionals working with individuals with autism. In a fully online ABA course, graduate students obtained significantly higher scores in posttests than in pretests on the instructional content delivered via the ATS training modules (Fielding, 2012). Although Fielding's study indicated that ATS produced a positive effect on student quiz scores, quiz scores on materials not taught through ATS in the online course were not reported and compared. Lee and Chang (in press) also reported that students scored significantly higher in weekly quizzes when ATS was used to supplement textbook readings accompanied with guided notes, compared to scores in weekly quizzes when ATS was not added. Young-Pelton and Doty (2013) employed the ATS modules as part of a training program to teach special education teachers evidence-based practices for students with autism. The survey results from the teachers indicated that the ATS online training was very helpful for their classroom implementation of evidence-based practices. However, the learning outcomes of teachers' knowledge and skill acquisition on evidence-based practices were not directly measured via assessments or observations. McCulloch and Noonan (2013) utilized the ATS mand (request) training modules along with a self-checklist to instruct paraprofessionals how to teach children with autism to make requests. They found that two out of three paraprofessionals effectively acquired the skills to implement mand training after the receiving the training package. The finding of the above ATS research highlights the potential utility and benefits of incorporating ATS in an online ABA course.

Review of the current literature suggests both guided notes and ATS may facilitate knowledge acquisition through online learning for university students. However, no study was conducted to compare the effect of using guided notes versus ATS to supplement textbook readings on student quiz performance in an online course. Additionally, use of guided notes in an online format has not been evaluated. In response to the gap, the purpose of the present study was to a) compare the effects of guided notes and ATS modules on the acquisition of basic ABA knowledge and b) evaluate the effect of guided notes on the maintenance of acquired knowledge for graduate students registered in a fully online ABA course. All students used an ABA textbook but acquired the knowledge contained in the textbook in two conditions: the guided notes condition and the ATS condition. The research questions are as follows: a) compared to the guided notes condition, did students perform differently on weekly quiz scores under the ATS condition? and b) under the guided notes condition, did students acquire and maintain the knowledge at least one week following the completion of the instruction? The survey results of students' perceived helpfulness and preference on guided notes and ATS were also reported.

\section{METHOD}

\section{Participants}

A total of 15 graduate students ( 14 females and one male) between the ages of 22 to 30 participated in this study. The students were enrolled in a Master program in Special Education with a focus on ASD and had various levels of previous knowledge and experience in ABA. Five students were dual-enrolled in the ABA certificate program in preparation for a board-certified behavior analyst credential. The course consisted of a total of 22 students. The seven students who elected not to participate had similar characteristics to the 15 participants and completed all of the assigned requirements for this course.

\section{Setting and Materials}

The study was conducted in an introductory course for graduate students entitled, "Applied Behavior Analysis." The instruction was delivered $100 \%$ online in an asynchronized format through the University's long-distance learning platform (Desire2Learn; D2L). The instructor posted the materials in $\mathrm{D} 2 \mathrm{~L}$, and the students retrieved the materials at the time of their convenience and completed the 
requirements within a specified period of time. The course was organized based on the content in the Applied Behavior Analysis Second Edition textbook (Cooper, Heron, \& Heward, 2007), supplemented with guided notes in D2L and selected video modules from the ATS web-based video training.

The guided notes were created by the course instructor based on the assigned textbook chapters and posted in D2L to guide students through reading the materials. Each unit of guided notes contained key points of the assigned chapters with approximately 120 to 180 fill-in-the-blanks for the students to fill in keywords or phrases. It took approximately 1.5 to 2.5 hours to complete guided notes each week. The D2L automatically graded the guided notes and showed correct answers to the students immediately upon submission. The D2L also recorded each student's history of completion.

The ATS contains learning modules related to specific ABA concepts presented in the format of short videos followed by competency test questions. Each module consists of a pretest with multiple choice questions, several 5 to 10-min videos with narratives and demonstrations of teaching procedures along with competency check questions, and a posttest identical to the pretest questions. Progression to the next video is contingent upon $100 \%$ accuracy on the competency questions with unlimited opportunities to mastery. If a learner does not meet the mastery criterion on competency checks, the system requires the learner to review the video presentation and repeats the competency check questions until mastery. Modules within each topic vary, and the total duration to complete one topic ranges from 1.5 to 2.5 hours. All ATS modules were delivered through the company's website. The participant's history of completion was recorded in their individual accounts and accessible to the course instructor.

\section{Dependent Measures}

\section{Weekly Quizzes}

The primary dependent variable was student scores on weekly quizzes. Each quiz consisted of 20 questions, with 14 multiple choice questions, two multiple select questions, and 4 fill-in-the-blank questions. The quiz questions were created based on the content of the assigned textbook readings for the week involving memorization and discrimination of basic learning principles and concepts, as well as their applications in applied settings. Each multiple-choice question had one designated correct answer, and each multiple-select question had two to four correct answers. Each fill-in-theblank question had one or two blanks of key terms for students to complete. Students had 30 minutes to complete each quiz. The D2L displayed time left to the student taking the quiz and automatically submitted the quiz at the end of 30 minutes. The students were required to complete the quizzes independently without sharing the content with other students.

\section{Baseline and Maintenance Test}

The test used in baseline and maintenance contained a total of 30 questions with 15 questions chosen from the materials taught under the guided notes condition and 15 questions chosen from the materials taught under the ATS conditions. The questions of the baseline and maintenance test consisted of three questions (two multiple questions and one fill-in-the-blank question) randomly selected from each of the five weekly quizzes administered under each condition. Thus, the test included 10 multiplechoice and five fill-in-the-blank questions from each condition, for a total of 20 multiple-choice and 10 fill-in-the-blank questions.

\section{Course Materials Evaluation Survey}

The course materials evaluation survey contained eight questions with four questions related to the guided notes and four related to the ATS for the purpose of assessing student perceptions of the usefulness of and satisfaction with the two types of instructional materials (Table 3). The survey questions were modified from the questionnaire in Lee and Chang (in press). Each item of the survey was rated on a 5 -point Likert scale $(0=$ strongly disagree to $4=$ strongly agree $)$. 
Survey questions were grouped into two categories: learning-related items (items 1 to 6) and enjoyment-related items (items 7-8) (See Table 3). The first six items were further grouped into three guided notes items (Cronbach's $\alpha=.0 .87$ ) and three ATS-related items (Cronbach's $\alpha=.86$ ). Student responses on perceptions about the guided notes and ATS were also compared.

\section{Experimental Design}

The study used an adapted alternating treatments single subject design (Wolery, Gast, \& Ledford, 2014) with statistical data analysis to compare the condition differences within a group of participants. A pre and posttest group design was incorporated to evaluate the effectiveness of guided notes in online learning. The sequence of this study consisted of a baseline test, ABABBBBAAA, and a maintenance test. A represents the guided notes condition and B represents the ATS condition. All students were taught with the same content in the same order of the conditions each week throughout the semester. The baseline test was administered in D2L during the first week of the semester, where student access to the course materials was contingent upon the completion of the baseline test. The order of conditions was determined by identifying the ATS modules applicable to supplement the textbook chapters in a given week in the course sequence. The maintenance test was administered as an extra credit opportunity on the last week of the semester, which was one week following the last experimental condition.

\section{Procedure}

The course was delivered fully online via D2L over a 15-week semester. Only 10 out of 15 course sessions were selected for assessment within the current study. Three sessions with content that continued from the preceding session were excluded to avoid a potential carry-over effect. The ethics session and the final exam week were not included. Each topic selected from the textbook consisted of distinct behavioral concepts and principles. The topic selection process attempted to control the difficulty level and to mitigate potential interference among materials presented each week between two conditions.

All instructional materials were prepared and uploaded to D2L, and the course was available to the students on the first day of the semester. The course had one instructor designing and implementing the course materials with one teaching assistant responsible for grading the written assignments. The students were required to complete the assigned readings from the textbook and to complete either the accompanied guided notes to criterion for the weeks under the guided notes condition or the assigned ATS modules to criterion for the weeks under the ATS condition. The D2L automatically unlocked the weekly quiz for each student once the student completed the required guided notes or ATS modules. Additionally, students completed two written projects by conducting a functional behavior assessment and developing a behavior change plan for a student in their work setting. All students in this study completed $100 \%$ of the course requirements.

\section{Baseline Test}

On the first day of the semester, the course website was made available to all students. The students were required to complete the baseline test before D2L released the access to the materials of the first week. The total time allowed was 40 minutes for the baseline test. No criterion was set for the baseline test to unlock the course materials, but the students were encouraged to answer the questions to the best of their knowledge. They were also informed that the baseline test would not be awarded to their final grade.

\section{Guided Notes Condition}

The guided notes condition was implemented during the first, third, 10th, 12th, and 13th weeks of the course covering the topics of ABA introduction, evaluation/analysis of behavior change, antecedent control, contingency/self-management, and generalization. Under the guided notes condition, the 
students were required to read the assigned readings and complete the notes in D2L to at least $80 \%$ accuracy before the weekly quiz was released. The students were given unlimited opportunities and time to complete the notes until mastery criterion was achieved. The D2L system provided the student with the percentage of accuracy along with correct answers immediately upon submission. If the student achieved criterion, D2L would automatically unlock the weekly quiz. If the student did not meet criterion, the student had to complete the guided notes until criterion in order to access the weekly quiz. There was a total of five quizzes completed under this condition.

\section{ATS Condition}

The ATS condition was implemented during the second, fourth, fifth, seventh, and ninth weeks of the course covering the topics of defining/measuring behavior, reinforcement, functional assessment, function-based intervention, and antecedent interventions. Under the ATS condition, the students were required to complete the assigned readings and the ATS modules. As described, the students also had to go through each component in the ATS learning modules in sequence and achieve mastery criterion on competency questions. If the student failed to meet criterion on competency checks, the learning system automatically went back to the video presentation followed by the same competency questions until mastery.

When students completed the ATS modules, they reported to D2L in order to unlock the quiz of the week. The teaching assistant checked the accuracy of student reports on ATS module completion to ensure that students completed the assigned ATS modules prior to taking the quiz. All students accurately reported their ATS completion. Students were allowed to take each weekly quiz up to two times with the average of the scores as their final grade. Only the first quiz score was used for this study. Upon the completion of each quiz attempt, D2L automatically graded the quiz and displayed the results to the student. There was a total of five quizzes under this condition.

\section{Course Material Evaluation Survey}

The survey was administered through D2L during the $13^{\text {th }}$ week of the course after they experienced both conditions for 10 weeks. The students were required to complete the survey to access the quiz of that week.

\section{Maintenance Test}

The maintenance test was administered one week after the last experimental condition during the final examination week of the semester. To limit opportunities for additional practice, the students were not informed of the test ahead of time and given short notice about the opportunity to receive extra credit for completing the test. The students were required to complete the test within four days. All students completed the test.

\section{Data Analysis}

The non-parametric statistical techniques for data analysis were used due to a small sample size. The Wilcoxon signed rank tests (Kaufhold, 2007) were used to compare the differences in scores of weekly quizzes, the baseline test, and the maintenance test, as well as the ratings of course materials used between the guided notes conditions and the ATS condition. The Wilcoxon signed rank tests were also used to assess the change in scores of the baseline and maintenance test on the guided notes and the ATS conditions. The Cohen's $d$ effect sizes were calculated using the formula $d=\left(\mathrm{M}_{\text {diff }} / \mathrm{SD}_{\text {average }}\right)$ $/ \sqrt{2(1-r)}$ with the consideration of dependence between pre and posttests corrected (Morris \& DeShon, 2002). In the formula, $\mathrm{M}_{\text {diff }}$ is the baseline test and maintenance test mean difference, $\mathrm{SD}_{\text {average }}$ is the average of SDs of baseline and maintenance tests, and $r$ is the Spearman's rho correlation between the baseline test and the maintenance test. An effect size of 0.2 indicates a small effect, 0.5 a moderate effect, and 0.8 a large effect (Cohen, 1988). 


\section{RESULTS}

\section{Condition Differences in Weekly Quizzes, Baseline, and Maintenance}

Table 1 displays results of the Wilcoxon signed rank tests (Kaufhold, 2007) of condition differences on student weekly quizzes, the baseline test, and the maintenance test. Students performed significantly higher scores in their weekly quizzes $(\mathrm{Z}=-3.18, p<.001)$ under the ATS condition $(M=17.31$, range $=15.5-18.07)$ than the guided notes condition $(M=16.07$, range $=14.93-17.67)$. The effect size was large $(d=0.97)$. No condition difference was found in baseline $(Z=-0.94, p=.35, d=$ $0.17)$ and maintenance $(Z=-.82, p=.42, d=0.14)$, suggesting that student performance was similar under both conditions during baseline and maintenance tests.

Table 2 displays descriptive data of means and standard deviations $(S D)$ for each student under the two conditions. All students, except Student 3, had a higher mean score under the ATS condition compared to the guided notes condition. The $S D s$ ranged from 0.71 to 2.88 under the guided notes condition and from 0.55 to 3.21 under the ATS condition.

\section{Change in Scores from Baseline to Maintenance by Condition}

Guided notes were provided as an option after the weekly quizzes under the ATS condition. If the students opted to complete guided notes after weekly quizzes in the ATS condition, the scores of the questions taught with ATS in the maintenance test may be influenced by guided notes besides ATS. Data in D2L show that nine to 11 students opted to complete guided notes in those weeks. Therefore, only the test scores under the guided notes condition were used to interpret the effect of guided notes on student knowledge acquisition.

Results indicate that there was a significant increase between baseline and maintenance test scores under both the guided notes condition $(Z=-3.41, p<.000)$ and the ATS condition $(Z=-3.41, p<$ .000 ), suggesting a significant increase in scores on materials taught under both conditions, likely as a result of overall instruction. Descriptive data indicated that student maintenance test scores was similar under the guided notes condition $(M=12.06$, range $=9-15)$ and the ATS condition $(M=11.8$, range $=9-15)$. The effect sizes were large for both the guided notes $(d=2.73, r=0.01)$ and the ATS condition $(d=2.72, r=0.22)$. The significant increase in scores from baseline to maintenance test and a large effect indicate the guided notes was an effective teaching method in the online course.

Table 1. Mean, standard deviation (SD), and effect sizes of test scores and survey ratings by condition

\begin{tabular}{|c|c|c|c|c|c|c|}
\hline $\mathbf{N}=\mathbf{1 5}$ & $\begin{array}{c}\text { Guided notes } \\
M(S D)\end{array}$ & $\begin{array}{c}\text { ATS } \\
M(S D)\end{array}$ & $z$ & $p$ & Cohen's $d$ \\
\hline Test Scores & & & & & & \\
\hline Weekly Quizzes & $16.07(1.28)$ & $17.31(1.26)$ & -3.18 & $.001 * * *$ & 0.49 & 0.97 \\
\hline Baseline & $5.8(1.37)$ & $6.13(1.64)$ & -0.94 & .35 & 0.14 & 0.17 \\
\hline Maintenance & $12.07(1.89)$ & $11.8(1.7)$ & -.82 & .42 & 0.38 & 0.14 \\
\hline Survey Ratings & & & & & & \\
\hline Helpfulness & $2.78(1.04)$ & $3.38(0.68)$ & -1.82 & .07 & & \\
\hline Enjoyment & $2.13(1.64)$ & $3.47(0.52)$ & -2.62 & $.009 * * *$ & & \\
\hline
\end{tabular}

Note. The Wilcoxon signed rank test was used to test condition differences; The total score for each weekly quiz was 20. Each student completed five quizzes under the guided notes condition and five quizzes under the ATS condition. The baseline test and maintenance test contained identical 30 questions with 15 guided notes condition questions ( 15 points total) and 15 ATS condition questions ( 15 points total); ${ }^{* *} p<.001$. (two-tailed); r Spearman's rho correlation between the guided notes and ATS conditions; Cohen's $\mathrm{d}$ : 0.2 small effect, 0.5 moderate effect, 0.8 large effect. Survey ratings: $0=$ strongly disagree, 1 = disagree, 2 = neutral, 3 = agree, and 4 = strongly agree. Helpfulness of guided notes (survey items 1, 2, and 5); Helpfulness of ATS (survey items 3, 4, and 6); Enjoyment of guided notes (survey item 7); Enjoyment of ATS (survey item 8). 
Table 2. Mean, range, standard division (SD) of student weekly quiz scores performed under the guided notes and ATS conditions for each student

\begin{tabular}{|c|c|c|c|c|}
\hline & \multicolumn{2}{|c|}{ Guided Notes } & \multicolumn{2}{|l|}{ ATS } \\
\hline & Mean (Range) & $S D$ & Mean (Range) & $S D$ \\
\hline Student 1 & $17.6(15-19)$ & 1.67 & $18.4(16-20)$ & 1.82 \\
\hline Student 2 & $15.4(11-18)$ & 2.61 & $16.2(12-19)$ & 2.95 \\
\hline Student 3 & $15.7(13-18)$ & 2.28 & $15.3(14.5-17)$ & 0.97 \\
\hline Student 4 & $14.6(11-17)$ & 2.3 & $17.2(13-19)$ & 2.39 \\
\hline Student 5 & $15.4(11-19)$ & 2.88 & $17.8(17-19)$ & 0.84 \\
\hline Student 6 & $14.6(11-17)$ & 2.19 & $14.74(12-16)$ & 1.64 \\
\hline Student 7 & $17.4(16-18)$ & 0.89 & $18.6(18-19)$ & 0.55 \\
\hline Student 8 & $14.2(12-17)$ & 1.92 & $17.74(15-19)$ & 1.74 \\
\hline Student 9 & $16.2(15-18)$ & 1.3 & $16.8(16-18)$ & 0.84 \\
\hline Student 10 & $16.1(15-18)$ & 1.82 & $16.4(11-18)$ & 3.21 \\
\hline Student 11 & $16.5(15.5-17)$ & 0.71 & $17.1(13.5-19)$ & 2.25 \\
\hline Student 12 & $18(17-20)$ & 1.22 & $19(17-20)$ & 1.41 \\
\hline Student 13 & $15.4(14-18)$ & 1.52 & $17.2(14-19)$ & 2.05 \\
\hline Student 14 & $15.6(12-18)$ & 2.19 & $18.6(17-20)$ & 1.52 \\
\hline Student 15 & $18.4(16-20)$ & 1.52 & $18.6(16-20)$ & 1.95 \\
\hline Total & $16.07(14.93-17.67)$ & 1.28 & $17.31(15.5-18.07)$ & 1.26 \\
\hline
\end{tabular}

Note. The total score for each quiz was 20. Each student completed five quizzes under the guided notes condition and five quizzes under the ATS condition.

The average percentage of accuracy for all students was $80.3 \%$ in weekly quizzes and $80.44 \%$ in maintenance for materials taught under the guided notes condition. Since the maintenance test was administered one week after the due date for the last weekly quiz, results of the maintenance test also indicate materials acquired under the guided notes condition were maintained at a high level at least one week following the completion of the instruction. The means and standard deviations in baseline and maintenance tests are displayed in Table 1.

\section{Course Materials Evaluation Survey}

The results of the Wilcoxon signed-rank tests on survey ratings were summarized in the lower panel of Table 1. No significant difference was found $(Z=-1.82, p=.07)$ between the student perceived ratings of learning related to the guided notes items $(M=2.78)$ and ATS items $(M=3.38)$, suggesting students perceived that they learned similarly from each type of material. However, the students reported a higher level of enjoyment $(Z=-2.62, p=.009)$ with ATS materials $(M=3.47)$ over the guided notes $(M=2.13)$, suggesting students enjoyed ATS significantly more than guided notes. The distribution of ratings for each item is summarized in Table 3.

\section{DISCUSSION}

The purpose of the present study was to compare the effects of guided notes and ATS modules as a supplement to textbook readings on student weekly quiz scores as well as evaluate the effectiveness of guided notes in a fully online ABA course. The student's perceived helpfulness and enjoyment 
Table 3. Satisfaction survey questions and ratings

\begin{tabular}{|l|c|c|c|c|}
\hline \multicolumn{1}{|c|}{$\mathbf{N = 1 5}$} & Category & $\begin{array}{c}\text { Frequency } \\
\text { Distribution } \\
\mathbf{0 - 1 - 2 - 3 - 4}\end{array}$ & Mean/Mode & SD \\
\hline $\begin{array}{l}\text { 1. The guided notes helped me learn the } \\
\text { information. I feel that I know more about the } \\
\text { topics after going through the guided notes. }\end{array}$ & Guided notes & $2-0-0-9-4$ & $2.87 / 3$ & 1.25 \\
\hline $\begin{array}{l}\text { 2. The guided notes helped me to prepare for the } \\
\text { quizzes. }\end{array}$ & Guided notes & $0-2-1-4-8$ & $3.2 / 4$ & 1.08 \\
\hline $\begin{array}{l}\text { 3. The ATS modules helped me to learn the } \\
\text { information. I feel that I know more about the } \\
\text { topics after going through the modules. }\end{array}$ & ATS & $0-0-1-3-12$ & $3.67 / 4$ & 0.62 \\
\hline $\begin{array}{l}\text { 4. The ATS modules helped me to prepare for the } \\
\text { quizzes. }\end{array}$ & ATS & $0-1-1-6-7$ & $3.27 / 4$ & 0.88 \\
\hline $\begin{array}{l}\text { 5. What I learned from the guided notes helped me } \\
\text { to do the project/assignment. }\end{array}$ & Guided notes & $1-3-4-5-2$ & $2.27 / 3$ & 1.16 \\
\hline $\begin{array}{l}\text { 6. What I learned from the ATS modules helped me } \\
\text { to do the project/assignment. }\end{array}$ & ATS & $0-0-3-6-6$ & $3.2 / 3,4$ & 0.77 \\
\hline 7. I enjoyed guided notes. & Guided notes & $4-2-1-4-4$ & $2.06 / 0,3,4$ & 1.64 \\
\hline \begin{tabular}{l} 
8. I enjoyed the ATS modules. \\
\hline
\end{tabular} & ATS & $0-0-0-8-7$ & $3.47 / 3$ & 0.52 \\
\hline
\end{tabular}

Note. This table displays the category of survey questions (guided notes/ATS), frequency distribution of ratings, mean/mode, and standard deviation for each question. Ratings: 0 = strongly disagree, $1=$ disagree, $2=$ neutral, $3=$ agree, and $4=$ strongly agree.

of course materials were also assessed. Results indicated that students scored significantly higher on weekly quizzes with materials taught under the ATS condition than under the guided notes condition. Student scores in the maintenance test were significantly higher than scores in the baseline test for materials taught under both conditions, indicating the positive results of overall instruction. Maintenance on materials taught with guided notes was also evident, but the maintenance effect on materials taught with ATS remains unclear. Additionally, survey results indicate that students did not perceive guided notes or ATS as being more helpful to their learning than the other, but rated their enjoyment with ATS greater than guided notes.

Student performance on weekly quizzes was better under the ATS condition than the guided notes condition. This is consistent with previous ATS research findings indicating the positive effects of adding ATS as part of the instruction on student quiz performance in an online course (Fielding, 2012; Lee \& Chang, in press). In Lee and Chang (in press), students scored significantly higher scores in weekly quizzes when ATS was added along with guided notes as a supplement to textbook readings. Instead of the additive effect, this study demonstrated the sole effect of ATS by comparing guided notes on student quiz scores as a supplement to a standard textbook under two separate conditions. Additionally, Fielding (2012) only used the pre and posttests questions (all multiple choice) contained in ATS to evaluate student acquisition specifically to the ATS content. In this study, quiz questions requiring various types of responses (i.e., multiple choice, multiple select, true/false, and short answers) were composed by several instructors based on the objectives of course content in a standard textbook. Thus, the results indicate the ATS modules relevant to the course content enhanced student knowledge acquisition demonstrated in weekly quizzes with different types of responses.

Although both guided notes and ATS were effective, data suggest student scores in weekly quizzes on materials taught under the ATS condition were higher than the guided notes condition. The major the differences between these two teaching methods is that ATS modules include video demonstrations on the applications of behavioral principles, while guided notes emphasize written responses. Compared to written responses involving active student participation, video demonstrations 
seem to be relatively passive in the process. However, video demonstrations provide visual models with auditory narratives for observational learning in the process, which may be critical to basic ABA knowledge acquisition. Future researchers can analyze and compare differences in learning outcomes resulting from acquisition processes involving video demonstrations versus written responses.

Another potential attribute to the highlighted importance of video demonstrations is likely related to student exposure to instructional practices derived from ABA principles. As described, the majority of students in this study were special education teachers who had limited or no exposure to ABA-related practices in their work settings. Thus, video demonstrations which visualized "ABA in action" could possibly enhance acquisition of basic ABA knowledge for these students. It is also necessary for future research to examine the differential effects of ATS or any video-based instruction for learners with or without practical training experience in ABA.

Both guided notes and ATS modules were effective in increasing student knowledge acquisition in an online course. Their effectiveness in learning was attributed to the incorporation of behavioral learning principles for active learning, including active student participation, small units of instruction, frequent unit quizzes, the mastery requirement, and individualized pacing. The aforementioned features were essential components in effective instruction demonstrated either in the traditional classroom (e.g., Boyce \& Hineline, 2002; Keller, 1968) or in an online learning environment (e.g., Pear \& Crone-Todd, 1999; Walker \& Rehfeldt, 2012). The key to effective instruction relies on how evidence-based strategies were integrated into the program, but not on its format of delivery (Skinner, 1968; Twyman, 2015).

Scores on the test administered before and after the instruction indicate a significant increase from baseline to maintenance under both conditions, suggesting the overall effectiveness of instruction. Consistent with previous guided notes research conducted in the classroom for college students (Konrad et al., 2009; Larwin \& Larwin, 2013; Reed et al., 2016), the result of this study also supports the effectiveness of using guided notes to enhance student learning in an online format. The average percentage of accuracy in the maintenance test was at a similar level as weekly quizzes for materials taught under both conditions, suggesting materials acquired throughout the semester were maintained one week following the completion of the instruction. The maintenance effect of guided notes is evident. However, maintenance scores for materials taught under the ATS condition must be interpreted with caution because guided notes were available after the completion of weekly quizzes under the ATS condition. The majority of students opted to take guided notes after they completed weekly quizzes in these weeks. Therefore, guided notes still had an impact on scores in the maintenance test for materials taught in ATS weeks. The overall results of this study indicate the immediate effect of ATS to increase weekly quiz scores but its maintenance effect remains questionable. It is necessary for future researchers to withdraw guided notes in ATS weeks in order to evaluate the maintenance effect of ATS and to compare whether differences exist in maintenance between guided notes and ATS.

Consistent with Lee and Chang (in press), survey results also indicated that students rated their enjoyment of ATS significantly higher than that of guided notes, albeit they did not perceive either one as more helpful in their learning. This finding provides additional support for the addition of ATS in an online ABA course. As discussed, the major difference is that ATS provides video demonstrations while guided notes emphasize on written responses. It is possible that the video demonstrations combined with other instructional strategies in ATS enhanced learning enjoyment for students.

It is important to note that 8 out of 15 students reported that they also enjoyed guided notes. The student's preference of instructional methods may be related to each individual's learning style shaped by their past learning history. That is, if a student has used guided notes in other courses and been successful in learning the materials, s/he is more likely to prefer guided notes over other types of teaching methods. If not, s/he may have a stronger preference to learn in an environment with multi-modal sensory stimulation as in the ATS condition over reading and writing textual responses as in the guided notes condition. However, such assertions warrant further investigation. 
Limitations of this study include a small sample size, lack of assessments on differences in content, different mastery criteria required in the two conditions, potential carry-over effects, no comparison of maintenance effects for materials taught under the two conditions, and the lack of control of student exposure to ABA practices in applied settings. Besides the small number in size, the sample contained over $93 \%$ of females enrolled in a particular course in a public research university in the Midwest region of the US. Therefore, the sample was not representative of university online learners. Future researchers may increase the sample size by implementing the same procedure to other cohorts of students from the following years or other universities. The increased sample size may increase representativeness and justify the use of parametric techniques for maximized statistical powers.

In this study, the difficulty level of the content for each chapter was not assessed. Differences in mastery criterion requirements in both conditions can also be another confounding variable. It is important that these potential pre-existing differences are ruled out to avoid confounds in future studies.

The potential carry-over effects were mitigated by checking the chapter content to ensure no overlaps of content assigned to both conditions and excluding weeks with the same topics. However, the risk of carry-over effect was not completely eliminated, especially for weeks toward the end of the semester where the learning outcomes may be related to cumulative learning experiences. Due to limited ATS modules relevant to the course content, it is also impossible to reverse the order between guided notes and ATS with another group of students.

For ethical reasons, guided notes were not completely withdrawn and provided as an option for extra credit in the ATS condition. Such an option hinders the evaluation of ATS's overall effectiveness in student knowledge acquisition throughout the semester as well as the comparison of maintenance effects between scores on materials taught under the two conditions. It is possible that future researchers can consider removing guided notes in the ATS condition to allow the overall evaluation of ATS and the comparison of maintenance effects.

The lack of control on student exposure to ABA practical experiences also limits the interpretation of results in this study. Of the 15 students in this study, only five students enrolled in the ABA certificate program possessed concurrent independent field experience in applied settings. The majority of the students were special education teachers who had limited or no contact with ABA in practical settings. The amount of exposure to ABA practices in applied settings may have an effect on student knowledge acquisition under the two conditions. This assertion warrants further investigation.

Additionally, the cost of ATS subscription was added to each student, and this can be a concern especially for students who are from an underprivileged background with financial burdens. In this case, instructors may consider supplementing the online course with recorded video demonstrations or utilizing freely available resources via education websites. Future researchers can examine whether supplementing textbook content with video demonstrations or external websites were effective in facilitating student acquisition of ABA knowledge.

The findings of this study have important implications for university instructors teaching courses in an online format. Results support the use of guided notes and video training modules as a supplement to a standard textbook to improve student performance of quiz scores. Instructors may consider including videos as part of the instruction to increase students' motivation and interest to engage in active learning in an online course.

\section{FUNDING}

This research project was funded by Michigan Department of Health and Human Services.

\section{DISCLOSURE OF POTENTIAL CONFLICTS OF INTEREST}

The author declares no conflict of interest. 


\section{REFERENCES}

Austin, J. L., Lee, M. G., Thibeault, M. D., \& Bailey, J. S. (2002). Effects of guided notes on university students' responding and recall of information. Journal of Behavioral Education, 11(4), 243-254. doi:10.1023/A:1021110922552

Bahadourian, A. J., Tam, K. Y., Greer, R. D., \& Rousseau, M. K. (2006). The effects of learn units on student performance in two college courses. The International Journal of Behavioral Consultation and Therapy, 2(2), 246(19).

Boyce, T. E., \& Hineline, P. N. (2002). Interteaching: A strategy for enhancing the user-friendliness of behavioral arrangements in the college classroom. The Behavior Analyst, 25(2), 215-226. doi:10.1007/BF03392059 PMID:22478388

Buzhardt, J., \& Semb, G. (2005). Integrating online instruction in a college classroom to improve cost effectiveness. Teaching of Psychology, 32(1), 63-66. doi:10.1207/s15328023top3201_12

Cohen, J. (1988). Statistical power analysis for the behavioral sciences (2nd ed.). Hillsdale, N.J: L. Erlbaum Associates.

Cooper, J. O., Heron, T. E., \& Heward, W. L. (2007). Applied behavior analysis (2nd ed.). Upper Saddle River, N.J: Pearson/Merrill-Prentice Hall.

Fielding, C. (2012). Online video instruction to graduate student autism class. Presented at the Annual Convention for Applied Behavior Analysis.

Fienup, D. M., Hamelin, J., Reyes-Giordano, K., \& Falcomata, T. S. (2011). College-level instruction: Derived relations and programmed instruction. Journal of Applied Behavior Analysis, 44(2), 413-416. doi:10.1901/ jaba.2011.44-413 PMID:21709803

Heward, W. L. (1994). Three "low-tech" strategies for increasing the frequency of active student response during group instruction. In Behavior analysis in education: Focus on measurably superior education (pp. 283-320). Pacific Grove, CA: Brooks/Cole.

Kaufhold, J. A. (2007). Basic statistics for educational research. New York: iUniverse, Inc.

Keller, F. S. (1968). Good-bye, teacher.... Journal of Applied Behavior Analysis, 1(1), 79-89. doi:10.1901/ jaba.1968.1-79 PMID:16795164

Konrad, M., Joseph, L. M., \& Eveleigh, E. (2009). A meta-analytic review of guided notes. Education \& Treatment of Children, 32(3), 421-444. doi:10.1353/etc.0.0066

Larwin, K. H., Dawson, D., Erickson, M., \& Larwin, D. A. (2012). Impact of guided notes on achievement in K-12 and special education students. International Journal of Special Education, 27(3), 108-119.

Larwin, K. H., \& Larwin, D. A. (2013). The impact of guided notes on post-secondary student achievement: A meta-analysis. International Journal on Teaching and Learning in Higher Education, 25(1), 47-58.

Martin, T. L., Pear, J. J., \& Martin, G. L. (2002a). Analysis of proctor marking accuracy in a computer-aided personalized system of instruction course. Journal of Applied Behavior Analysis, 35(3), 309-312. doi:10.1901/ jaba.2002.35-309 PMID:12365747

Martin, T. L., Pear, J. J., \& Martin, G. L. (2002b). Feedback and its effectiveness in a computer-aided personalized system of instruction course. Journal of Applied Behavior Analysis, 35(4), 427-430. doi:10.1901/jaba.2002.35427 PMID: 12555917

McCulloch, E. B., \& Noonan, M. J. (2013). Impact of online training videos on the implementation of mand training by three elementary school paraprofessionals. Education and Training in Autism and Developmental Disabilities, 48(1), 132-141.

Morris, S. B., \& DeShon, R. P. (2002). Combining effect size estimates in meta-analysis with repeated measures and independent-groups designs. Psychological Methods, 7(1), 105-125. doi:10.1037/1082-989X.7.1.105 PMID:11928886 
Neef, N. A., McCord, B. E., \& Ferreri, S. J. (2006). Effects of guided notes versus completed notes during lectures on college students' quiz performance. Journal of Applied Behavior Analysis, 39(1), 123-130. doi:10.1901/ jaba.2006.94-04 PMID:16602392

Pear, J., \& Crone-Todd, D. (1999). Personalized system of instruction In cyberspace. Journal of Applied Behavior Analysis, 32(2), 205-209. doi:10.1901/jaba.1999.32-205

Reed, D. K., Rimel, H., \& Hallett, A. (2016). Note-taking interventions for college students: A synthesis and meta-analysis of the literature. Journal of Research on Educational Effectiveness, 9(3), 307-333. doi:10.1080 /19345747.2015.1105894

Sella, A. C., Ribeiro, D. M., \& White, G. W. (2014). Effects of an online stimulus equivalence teaching procedure on research design open-ended questions performance of international undergraduate students. The Psychological Record, 64(1), 89-103. doi:10.1007/s40732-014-0007-1

Skinner, B. F. (1958). Teaching Machines. Science, 128(3330), 137-158. doi:10.1126/science.128.3330.969 PMID:13592277

Skinner, B. F. (1968). The technology of teaching. New York: Appleton-Century-Crofts.

Twyman, J. S. (2015). Envisioning education 3.0: The fusion of behavior analysis, learning science and technology. Revista Mexicana de Análisis de la Conducta [Mexican Journal of Behavior Analysis], 40(2), 20-38. doi:10.5514/rmac.v40.i2.63663

U.S. Department of Education, National Center for Education Statistics. (2018). Digest of Education Statistics, 2016 (NCES 2017-094), Table 311.15. Retrieved from: https://nces.ed.gov/fastfacts/display.asp?id=80

U.S. Department of Health and Human Services. (1999). Mental health: A report of the Surgeon General. MD: U.S. Department of Health and Human Services, Substance Abuse and Mental Health Services Administration, Center for Mental Health Services, National Institutes of Health, National Institute of Mental Health.

Walker, B. D., \& Rehfeldt, R. A. (2012). An evaluation of the stimulus equivalance paradigm to teach singlesubject design to distance education students via Blackboard. Journal of Applied Behavior Analysis, 45(2), 329-344. doi:10.1901/jaba.2012.45-329 PMID:22844140

Wolery, M., Gast, D. L., \& Ledford, J. R. (2014). Comparison Designs. In D. L. Gast \& J. R. Ledford (Eds.), Single Case Research Methodology: Applications in special education and behavioral sciences (2nd ed., pp. 297-345). New York, NY: Routledge.

Young-Pelton, C. A., \& Doty, D. (2013). Improving educational programs for students with autism in rural schools: A preliminary program description of the Montana Autism Education Project. Rural Special Education Quarterly, 32(3), 24-32. doi:10.1177/875687051303200305 